\title{
ASCENSÃO E COLAPSO DA RAZÃO INSTRUMENTAL NEOLIBERAL
}

\author{
RISE AND COLLAPSE OF INSTRUMENTAL NEOLIBERAL REASON
}

Leomir Cardoso Hilário ${ }^{1}$

\begin{abstract}
RESUMO
O ponto de partida desse ensaio é o de que a noção de razão instrumental - elaborada por Adorno e Horkheimer nos anos 40 do século XX - ainda nos permite compreender a sociedade capitalista contemporânea. No entanto, para que essa noção produza efeitos de análise acerca da atualidade, é preciso compreender as modificações históricas que atravessam a segunda metade do século XX e o início do século XXI. Proponho, então, a noção de "razão instrumental neoliberal", demarcando as metamorfoses da racionalidade instrumental a partir da crise capitalista dos anos 1970, periodizando dois momentos: o de sua ascensão e o de seu colapso. Após apresentar a noção a partir de Adorno e Horkheimer e depois atualizá-la por meio de Brenner, Lasch e Sennett, problematizo o que significa, em termos sociais e psíquicos, viver em tempos de declínio da racionalidade instrumental, ou, em outras palavras, numa quadra histórica na qual o horizonte da sociedade capitalista deixou de ser o da produção de subjetividade para ser a destruição do psiquismo.
\end{abstract}

Palavras-chaves: Teoria Crítica. Razão Instrumental. Necropolítica. Neoliberalismo. Subjetividade.

\section{ABSTRACT}

This essay argues that the notion of instrumental reason - elaborated by Adorno and Horkheimer in the 1940s - still allows us to understand contemporary capitalist society. However, in order for this notion to produce analytical effects on the present, it is necessary to understand the historical changes that go through the second half of the twentieth century and the beginning of the twenty-first century. I propose, then, the notion of "instrumental neoliberal reason", demarcating the metamorphoses of instrumental rationality from the capitalist crisis of the 1970s, periodizing two moments: its rise and its collapse. After presenting the notion from Adorno and Horkheimer and then updating it through Brenner, Lasch and Sennett, I question what it means, in social and psychic terms, to live in times of declining instrumental neoliberal reason, or in other words, in a historical block in which the horizon of capitalist society shifted from the production of subjectivity to the destruction of the psyche.

Keywords: Critical theory. Instrumental reason. Necropolitics. Neoliberalism. Subjectivity.

\footnotetext{
${ }^{1}$ Atualmente é Professor Efetivo do Departamento de Psicologia - UFPI. Doutor em Psicologia Social - UERJ. e - mail: leomirhilario@yahoo.com.br
} 


\section{Revista (O) \\ Debates Insubmissos}

\section{INTRODUÇÃO}

A definição do tempo histórico atual como "grande regressão", tal como fez GEISELBERGER (2019), não pode ser encarada como pessimista. A sensação de viver num mundo que, por pior que seja, parece ainda melhor do que aquilo que virá é compartilhada por todos, principalmente pelas gerações mais novas. Produzir uma reflexão radical em tempos de regressão social é a tarefa mais fundamental da chamada teoria crítica da sociedade ou Escola de Frankfurt, como é mais conhecida. O contexto mundial atual se assemelha àquele analisado por intelectuais como Max Horkheimer, Theodor Adorno e Herbert Marcuse, dentre outros, razão pela qual devemos voltar a essa tradição para que possamos compreender o que está se passando, recuperando o nexo entre economia, sociedade e subjetividade.

Para tanto, estruturei essa escrita em três momentos: no primeiro, intitulado "As pistas do conceito: a racionalidade instrumental em Adorno e Horkheimer", estabeleço uma leitura da noção de racionalidade instrumental a partir dos intelectuais ligados à chamada "Escola de Frankfurt”, em específico Adorno e Horkheimer, historicizando essa noção no contexto do capitalismo que vigorou a pleno vapor durante uma parte do século XX. No segundo momento, chamado "A ascensão da razão instrumental neoliberal: da desregulação econômica à desregulação psíquica", aponto para a necessidade de repensar a noção de racionalidade instrumental devido às transformações do capitalismo, me apoiando nas leituras de Robert Brenner, que demonstram a implicação do Estado de Bem-Estar Social com o neoliberalismo e abrem caminho para pensar a desregulação econômica junto com a desregulação psíquica. Nesse quadrante histórico, de 1975 até pelo menos 1990, a razão instrumental neoliberal em expansão e consolidação conseguia minimamente produzir seus efeitos desejados em concomitância com a permanência da barbárie. Também buscarei pensar os impactos psíquicos dessa modalidade de racionalidade instrumental, a partir de Christopher Lasch e Richard Sennett. 


\section{novist

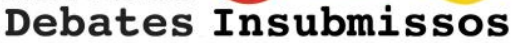

Já no terceiro momento, por fim, chamado "O mal-estar do pós-neoliberalismo", reflito acerca de como o capitalismo vem abandonando paulatinamente a tarefa de produção de subjetividade para, em seu lugar, pôr a destruição do psiquismo em primeiro plano. Aqui, a barbárie passa a ser a forma estruturante da razão instrumental neoliberal. Nesse sentido, como pensar um tempo histórico que prescinde da produção de subjetividade como elemento fundamental da reprodução da sociedade capitalista e que, por conta disso, se desfaz paulatinamente daquilo que a sustenta, a saber, os sujeitos? Esse momento consiste no colapso $^{3}$ da racionalidade instrumental neoliberal, cujos efeitos de barbárie se disseminam sem nenhum tipo de controle.

Ainda à guisa de introdução, a leitura da teoria crítica que desenvolvo aqui é marcada por aquilo que Freyenhagen (2018) chamou de "teoria crítica ortodoxa", cuja ênfase está nos insights dos pioneiros da Escola de Frankfurt, recusando a obrigatoriedade do giro linguístico e a necessidade de um programa de justificação, movimentos caros aos herdeiros de Frankfurt, em especial Habermas. Também me apoio em Stefan Gandler (2007), para quem é necessária uma atualização e radicalização por meio de uma teoria crítica periférica, apontando um horizonte de análise para além dos registros das gerações e da centralidade da experiência europeia.

\footnotetext{
${ }^{2}$ Até onde sei, essa expressão foi primeiramente utilizada por Jamie Peck, Nik Theodore e Neil Brenner (2012). Sobre esse exercício de diagnosticar o presente como "pós-neoliberalismo", conferir também a obra de Gérard Duménil e Dominique Lévy (2014).

3 O termo "colapso" possui uma longa tradição no interior do pensamento crítico e radical de esquerda, atravessando nomes como Rosa Luxemburgo, Henryk Grossmann e Paul Mattick. Utilizo aqui o conceito na perspectiva mais recente de Robert Kurz, onde "colapso" significa uma época histórica marcada pela tendência de declínio do capitalismo enquanto modo de produção de mercadorias e, consequentemente, também pela barbarização de toda a sociedade: "O colapso da relação de valor não começa apenas quando o último trabalhador for eliminado da produção imediata. Ele começa antes: precisamente no ponto histórico onde a relação geral entre a eliminação e a reabsorção do trabalho produtivo vivo imediato começa a se alterar, ou seja, já no momento (cada vez mais) onde (e como) é eliminado mais trabalho produtivo imediato do que é reabsorvido" (KURZ, 2018a, p. 64). Ou seja, o colapso não significa acordar de repente sem o capitalismo, mas sim a entrada num processo histórico socialmente turbulento e sem retorno possível (KURZ, 2018b). No contexto desse ensaio, falar em "colapso da racionalidade instrumental" é apontar para o esgotamento dos mecanismos que sustentavam a racionalidade instrumental em tempos neoliberais.
} 


\title{
2. NAS TRILHAS DO CONCEITO: A RACIONALIDADE INSTRUMENTAL EM ADORNO E HORKHEIMER
}

Há, pelo menos, quatro pistas da noção de racionalidade instrumental na Dialética do Esclarecimento. Em nenhuma delas aparece literalmente a expressão "racionalidade instrumental", no entanto, ela está sempre pressuposta. Vejamos a primeira pista:

\begin{abstract}
O pensar reifica-se num processo automático e autônomo, emulando a máquina que ele próprio produz para que ela possa finalmente substituí-lo. O esclarecimento pôs de lado a exigência clássica de pensar o pensamento - a filosofia de Fichte é o seu desdobramento radical - porque ela desviaria do imperativo de comandar a práxis, que o próprio Fichte no entanto queria obedecer. $\mathrm{O}$ procedimento matemático tornou-se, por assim dizer, o ritual do pensamento. Apesar da autolimitação axiomática, ele se instaura como necessário e objetivo: ele transforma o pensamento em coisa, em instrumento, como ele próprio o denomina (ADORNO; HORKHEIMER, 1985, p. 33, grifo nosso).
\end{abstract}

A razão instrumental aparece como resultado inesperado, porém lógico-histórico, da vontade esclarecida de se ver livre do mito, do obscurantismo e das trevas. Esse ato de libertação do mito se dá pela identificação com o pensamento calculador, o qual, por sua vez, constitui-se como fundamento da sociedade baseada na troca e na exploração. O pensamento identifica-se com o existente e, assim, abre mão da possibilidade de servir à humanidade e passa a servir à forma social fetichista do capitalismo. Vamos à segunda pista:

O positivismo - que afinal não recuou nem mesmo diante do pensamento, essa quimera tecida pelo cérebro no sentido mais liberal do termo - eliminou a última instância intermediária entre a ação individual e a norma social. O processo técnico, no qual o sujeito se coisificou após sua eliminação da consciência, está livre da plurivocidade do pensamento mítico bem como de toda significação em geral, porque a própria razão se tornou um mero adminículo da aparelhagem econômica que a tudo engloba. Ela é usada como um instrumento universal servindo para a fabricação de todos os demais instrumentos. Rigidamente funcionalizada, ela é tão fatal quanto a manipulação calculada com exatidão na produção material e cujos resultados para os homens escapam a todo cálculo. Cumpriu-se afinal sua velha ambição de ser um órgão puro dos fins (ADORNO; HORKHEIMER, 1985, p. 37, grifo nosso).

Em termos de crítica da ideologia, há uma passagem da conversão das discursividades amplas para a dominação concreta dos indivíduos, por um lado temos aquela dinâmica na qual a razão se instrumentaliza, onde "a própria razão se tornou um mero adminículo da aparelhagem econômica", "um órgão puro dos fins", por outro lado, "a expulsão do pensamento da lógica ratifica na sala de aula a coisificação do homem na fábrica e no 
escritório" (ADORNO; HORKHEIMER, 1985, p. 37). Quando este processo ocorre, significa que "o corpo já há muito foi ajustado pelo sistema" (ADORNO; HORKHEIMER, 1985, p. 41). Há esse paralelismo entre o mecanismo mais abstrato do fetichismo da mercadoria e a concretude do cotidiano dos indivíduos, além de como essas duas dimensões são essenciais para o modo de dominação social do capitalismo.

Em outro momento, já mais no final do livro, eles afirmam que "o poder recorria às relações de poder dominantes [...] ao mesmo tempo, a sociedade burguesa também desenvolveu, em seu processo, o indivíduo" (ADORNO; HORKHEIMER, 1985, p. 138). Ou seja, além do tema do entrelaçamento entre racionalidade e realidade social, esse tema das relações entre a sociedade e os indivíduos é central na Dialética do Esclarecimento. Ambos os temas se complementam: o modo pelo qual a sociedade moderna capitalista se constrói através da racionalidade instrumental cujo modelo é a forma-valor e a especificidade da inscrição social num quadro como este.

A quarta, e última, pista é a seguinte:

Semelhante à coisa, à ferramenta material - que pegamos e conservamos em diferentes situações como a mesma, destacando assim o mundo como o caótico, multifário, disparatado do conhecido, uno, idêntico - o conceito é a ferramenta ideal que se encaixa nas coisas pelo lado por onde se pode pegá-las (ADORNO; HORKHEIMER, 1985, p. 43, grifo nosso).

A racionalidade instrumental transforma o pensamento numa espécie de ferramenta capaz de manipular o mundo objetivo e subjetivo no sentido da exploração e do controle. Não foi somente na Dialética do Esclarecimento que se tematizou a racionalidade instrumental. Em um ensaio de 1951, Horkheimer (2002) destaca dois conceitos de razão antagônicos: um próprio dos grandes sistemas filosóficos desde Platão, que supõe a filosofia como imagem da essência racional do mundo, e uma razão subjetiva, formal, instrumental, que tem a ver com a relação entre fins e meios, com a adequação dos modos de comportamento aos fins, os quais, como tais, são aceitos sem que se os submeta a uma reflexão racional. A teoria crítica gira em do "problema da conexão entre a existência particular e a razão universal, entre a realidade e a ideia, entre a vida e o espírito; só que este velho tema aparece agora colocado numa nova constelação de problemas" (HORKHEIMER, 1999, p. 130). 


\section{noviste

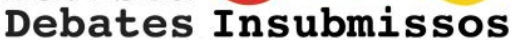

Em sua Crítica da Razão Instrumental, cujo título brasileiro é Eclipse da Razão ${ }^{4}$, a questão era a do "processo de subjetivação" (HORKHEIMER, 2002, p. 97) da razão objetiva, isto é, quando a Razão (Vernunft) se instrumentaliza, perde sua autonomia e abandona seu projeto de construção de um mundo racional. O positivismo é a forma-teórica adequada a este processo. Em resumo: “[...] se a própria razão é instrumentalizada, tudo isso conduz a uma espécie de materialidade e cegueira, torna-se um fetiche, uma entidade mágica que é aceita ao invés de ser intelectualmente aprendida" (HORKHEIMER, 2002, p. 28). A razão instrumental é a racionalidade sujeitada à irracionalidade do capital, ela denota o processo no qual a razão "se tornou algo inteiramente aproveitado no processo social" (HORKHEIMER, 2002, p. 26). Dessa forma, segundo suas próprias palavras, tenho cedido em sua autonomia, a razão tornouse um instrumento:

Os conceitos foram aerodinamizados, racionalizados, tonaram-se instrumentos de economia de mão-de-obra. É como se o próprio pensamento tivesse se reduzido ao nível do processo industrial, submetido a um programa estrito, em suma, tivesse se tornado uma parte e uma parcela da produção (HORKHEIMER, 2002, p. 26).

Em termos históricos, essa conexão entre o modo de produção de mercadorias e a racionalidade instrumental passou por fases de expansão e consolidação, ou seja, ainda que produzissem controle e barbárie, eram capazes de estabelecer, para regiões específicas da sociedade mundial, momentos de crescimento econômico e ganhos de bem-estar. Ainda que à serviço do capitalismo, a razão instrumental produzia civilização, alternada com instantes de barbárie, os quais poderiam ser lidos, ainda que erroneamente, como tropeços ou acidentes de percurso. Para compreender isso, devemos refletir acerca dos vínculos do processo de instrumentalização da razão com a realidade após a Segunda Guerra Mundial, o que se pode chamar de "núcleo temporal da racionalidade instrumental".

\footnotetext{
${ }^{4}$ Segundo Martin Jay (2008, p. 320), Eclipse da Razão, publicado pela primeira vez em inglês, em 1947 foi traduzido para o alemão como parte da Crítica da Razão Instrumental (Zur kritik der instrumentellen Vernunft), por Alfred Schmidt. A tradução espanhola conserva o mesmo título: Crítica de la razón instrumental, publicada pela Editorial Sur, em 1973.
} 
A legitimidade de se pensar a racionalidade instrumental para além do início do século XX está dada por Adorno e Horkheimer num dos prefácios à Dialética do Esclarecimento, datado de 1969:

O livro foi dirigido num momento em que já se podia enxergar o fim do terror nacional-socialista. Mas não são poucas as passagens em que a formulação não é mais adequada à realidade atual. E, no entanto, não se pode dizer que, mesmo naquela época, tenhamos avaliado de maneira excessivamente inócua o processo de transição para o mundo administrado. (ADORNO; HORKHIEMER, 1985, p. 9).

Parece claro que a noção de racionalidade instrumental é vista pelos autores como capaz de dar conta também da realidade pós-guerra, que Adorno denominou de "mundo administrado". A crítica da razão instrumental é parte do diagnóstico da modernidade embasado numa teoria crítica da autodestruição da razão por meio da instrumentalização da racionalidade moderna. Essa modalidade de razão serve aos fins de autoconservação da sociedade capitalista, a saber, o incremento do valor por meio do desenvolvimento das forças produtivas (técnica), da manipulação da natureza objetiva e do controle das formas subjetivas (do sofrimento e do mal-estar, p. ex.). A razão instrumental é, então, um conjunto de práticas de organização social e de estruturação subjetiva condicionadas aos imperativos de valorização do valor capitalista. Deste modo, a crítica da razão instrumental participa da dominação própria do arranjo histórico denominado "Capitalismo de Estado", conceito de autoria de Friedrich Pollock (1990), a quem inclusive A Dialética do Esclarecimento é dedicada.

$\mathrm{O}$ conceito de capitalismo de Estado diz respeito à preponderância do elemento político na gestão da sociedade capitalista, isto é, a ocorrência do "primado da política" sobre a economia. O mercado perde seu controle para coordenar a distribuição e produção, de tal modo que as leis econômicas desaparecem ${ }^{5}$. A tendência do sistema capitalista era, então, quaisquer que fossem seus avatares, o crescimento do controle estatal sobre a sociedade e o mercado. Pollock, com sua teoria da crise, fornecia um diagnóstico de época preciso que ia

\footnotetext{
${ }^{5}$ No original: "The market is deposed from its controlling function to coordinate production and distribution. This function has been taken over by a system of direct controls. Freedom of trade, enterprise and labor are subject to governmental interference of such a degree that they are practically abolished. With the autonomous market the so-called economic laws disappear" (POLLOCK, 1990, p. 72).
} 


\section{Revista \\ Debates Insubmissos}

mais além das formas fenomênicas da política e enfatizava o contexto histórico mais amplo no interior do qual as diversas formas de gestão do capitalismo se inscreviam: desde a União Soviética até o capitalismo norte-americano, passando pelo Estado de Bem-estar Europeu. Imune às crises, o capitalismo revigorava sua força sobre a sociedade por meio do controle político cujo objetivo era produzir uma espécie de congelamento do movimento histórico:

O controle governamental da produção e da distribuição proporciona os meios para a eliminação das causas econômicas das depressões, dos processos globalmente destrutivos, do desemprego e da falta de investimento. Poderíamos chegar ao ponto de dizer que sob o capitalismo de Estado a economia perdeu, como ciência social, seu objeto ${ }^{6}$ (POLLOCK, 1990, p. 87, trad. minha).

É importante lembrar de que na nota sobre a nova edição alemã da Dialética do Esclarecimento, escrita em 1969, Adorno e Horkheimer defendem a existência do núcleo temporal da teoria. Adorno expôs algo este respeito também em Ensaio como Forma, ao dizer: "Se a verdade tem, de fato, um núcleo temporal, então o conteúdo histórico torna-se, em sua plenitude, um momento integral dessa verdade; o a posteriori torna-se concretamente um a priori” (ADORNO, 2003 p. 26). Bem como em seus Três estudos sobre Hegel, ele defendeu que a verdade hegeliana não está nem no tempo, como o era a verdade nominalista, nem acima do tempo, segundo a forma ontológica: o tempo seria, em sua leitura de Hegel, "um momento da própria verdade". Portanto, "a verdade (...) possui um núcleo temporal" (ADORNO, 2013 p. 118). Em outro momento, em sua Introdução à dialética: "A exigência decisiva da dialética é que não se trata de buscar a verdade no tempo ou em oposição ao tempo, mas sim que a verdade mesma tem um núcleo temporal, isto é, o tempo está na verdade" (ADORNO, 2008, p, 53). O núcleo temporal da verdade é a capacidade do pensamento de produzir diagnósticos certeiros numa dada temporalidade histórica, de modo que se pode cambiar o termo verdade por teoria ou crítica. O núcleo temporal da teoria da crise da primeira geração frankfurtiana pode ser situado entre 1945-1975. Como mostrou Wolfgang Streeck (2013, p. 13):

\footnotetext{
${ }^{6}$ No original: "Government control of production and distribution furnishes the means for eliminating the economic causes of depressions, cumulative destructive processes and unemployment of capital and labor. We may even say that under state capitalism economics as a social science has lost its object" (POLLOCK, 1990, p. 87).
} 
O que era característico da teoria da crise da "Escola de Frankfurt" era o pressuposto heurístico da existência, por um lado, da relação de tensão fundamental entre vida social e, por outro, uma economia dominada pelos imperativos de valorização e multiplicação do capital - uma relação tensa que, de forma multifacetada e em contínua evolução histórica, foi transmitida na estruturação do capitalismo democrático pós-guerra.

Contudo, depois do breve período de estabilidade política e crescimento econômico, as crises voltaram com toda a força, abalando toda a paisagem do mundo elaborada na primeira metade do século XX. Esse núcleo temporal sai de cena e leva consigo boa parte das reflexões críticas produzidas mais ou menos até a primeira metade do século XX e impõe levar a sério a assertiva de Adorno (2009, p. 302): “o pensamento também precisa, para ser verdadeiro, hoje em todo caso, pensar contra si mesmo".

\section{A ASCENSÃO DA RAZÃO INSTRUMENTAL NEOLIBERAL: DA DESREGULAÇÃO ECONÔMICA À DESREGULAÇÃO PSÍQUICA}

Pretendo analisar a razão instrumental a partir da crítica da economia política, vinculando-a com a crise do capitalismo dos anos 1970 e a entendendo como expressão da dinâmica interna autocontraditória do capital, trazendo o problema do neoliberalismo para o campo da crítica do capitalismo e da crítica da razão instrumental. Em uma palavra: compreender o neoliberalismo como mais um giro no parafuso da razão instrumental na direção da barbárie. Num artigo sobre as tendências regressivas nas sociedades atuais, Oliver Natchwey também propõe essa aproximação entre neoliberalismo e razão instrumental:

\footnotetext{
O neoliberalismo, a crença quase religiosa no mercado, é uma encarnação da "razão instrumental". No âmbito do poder da razão instrumental, segundo Horkheimer, tudo é submetido a uma racionalidade de meios e fins, à lógica do domínio da natureza e da individualidade. (...) Sob a égide da razão instrumental total, entretanto, o controle do indivíduo sobre o mundo torna-se o controle total do mundo sobre o indivíduo. A individualidade conforme o mercado torna-se um imperativo social (NATCHWEY, 2019, p. 223).
}

Para realizar esse gesto vinculatório entre crise do capitalismo e racionalidade instrumental, pensada em seu avatar contemporâneo neoliberal, opto por analisar a ascensão do neoliberalismo a partir do historiador americano Robert Brenner. Ele participa daquilo que Jonathan Martineau (2013) chamou de "marxismo anglo-saxão", isto é, uma tradição 


\section{Revista
Debates Insubmissos}

intelectual marxista que se consolida após os anos 1960, cujas figuras marcantes são Perry Anderson, Edward P. Thompson, David Harvey, Moishe Postone, Derek Sayer, Simon Clarcke, Ellen M. Wood e David McNally. O caminho percorrido por esses intelectuais faz parte de uma renovação das teorias inspiradas em Marx no campo das ciências sociais de língua inglesa. Há três tendências nesse marxismo anglo-saxão: a crítica do reducionismo econômico e do determinismo; o retorno à história e a retomada da crítica da economia política de Marx. Todas elas seriam marcadas por um anti-dogmatismo e uma vontade de atualização da teoria crítica inspirada em Marx. Para Francis-Fortier e Louis-Philippe Lavallé (2013), três grandes problemáticas estão presentes na obra de Brenner: a que se refere à transição para o capitalismo, a questão concernente às especificidades da Revolução Inglesa e o problema do longo declínio (long downturn) da economia mundial após a década de 1970. Eu vou me concentrar apenas nesse último ponto, dado o foco desse ensaio.

A tese de Robert Brenner é relativamente simples, embora singular: para ele, não é estranho, mas sim lógico, que as economias capitalistas tenham entrado num estágio de declínio logo após os Trinta Anos Gloriosos (1945-1975). Mais do que isso, também é parte de uma lógica histórica que o período posterior tenha sido caracterizado pelo desmanche das supostas conquistas da Era de Ouro. Ou seja, a transição aparentemente abrupta da longa expansão (1945-1973) para um estágio de longo declínio é parte de um mesmo processo de concorrência internacional característico do sistema capitalista. Em outras palavras, a derrocada do Estado de Bem-Estar Social ocorreu pelas mesmas dinâmicas econômicas que o sustentaram durante quase três décadas. O longo declínio foi fruto de uma crise de superprodução no setor manufatureiro que se deu devido à concorrência entre as grandes economias capitalistas no contexto internacional, de tal modo que aquilo que garantiu o longo crescimento foi a condição de possibilidade para o longo declínio. Nas palavras de Brenner (2006, p. 37): "Foi essa combinação e interação entre os blocos de desenvolvimento mais 
novos e mais tardios o que determinou em grande medida o caráter da longa expansão e a natureza do longo declínio que veio depois"7.

É comum se falar em fordismo e pós-fordismo, porém, o que levou a passagem de um para o outro? Por que os acontecimentos não nos levaram a outros caminhos? O mesmo vale para a ascensão do neoliberalismo, em reação ao que ele se impôs, a quais problemas ele veio dar conta? Na ausência de uma explicação da passagem de uma conjuntura histórica à outra, a afirmação brenneriana de um fundamento comum ao longo boom e ao longo declínio mostra sua singularidade e pertinência.

O núcleo da análise brenneriana do período pós-guerra, portanto, é o modo como um elemento constitutivo do capitalismo, a concorrência, mina seus objetivos de expansão e crescimento econômicos. A nível internacional, ela se traduz num processo desigual pelo qual as nações retardatárias conseguem alcançar os líderes, empatando o capital fixo e adentrando mercados com mercadorias de baixo preço. Enquanto essa dinâmica funcionou bem, as principais economias capitalistas vivenciaram um crescimento sem precedentes: "O meu argumento é o de que as raízes da estagnação de longa duração e da crise atual estão na compressão dos lucros do setor manufatureiro que se originou no excesso de capacidade e de produção fabril, que era em si a expressão da acirrada competição internacional” (BRENNER, 1999, p. 13).

Brenner divide quatro períodos em sua análise: a longa expansão (1945-1965), a queda da rentabilidade e o iniciar da crise (1965-1973), o longo declínio (1973-1990) e o que se pode chamar de turbulência global (1990 até hoje). Durante o primeiro período, nações periféricas, como Alemanha e Japão, atingiram índices sem precedentes de acumulação de capital, devido ao atraso socioeconômico, puderam tirar vantagem das enormes reservas de desempregados e obter um crescimento salarial relativamente baixo em comparação ao

\footnotetext{
${ }^{7}$ No original: "It was the combination of and interaction between the older and later developing blocs that largely determined both the character of the long boom and the nature of the long downturn to which it gave rise" (BRENNER, 2006, p. 37).
} 
crescimento da produtividade. Uma espécie de vantagem do atraso. Tudo parecia funcionar muito bem:

O desenvolvimento econômico internacional pós-guerra dentro do mundo capitalista avançado pôde, por um breve período, manifestar um grau relativamente alto de cooperação internacional, ainda que sob dominação do Estado americano e predominantemente modelada pelos interesses americanos (BRENNER, 2003, p. 54).

Esta concorrência levou os países atrasados a empatarem o capital fixo com o americano, aumentarem significativamente sua produtividade e abarcarem partes cada vez maiores dos mercados internacionais, inundando-os com mercadorias de preço baixo. A nível geral, no entanto, enquanto as economias de desenvolvimento tardio conseguiam manter suas taxas de lucro dados os custos e preços mais baixos, os Estados Unidos foram incapazes de evitar sua queda de rentabilidade.

Assim, Brenner argumenta que o longo declínio foi fruto de uma intensificação da concorrência que deu lugar a um excesso de produção e uma longa queda da rentabilidade, principalmente na indústria ${ }^{8}$. Outras medidas foram tomadas. Uma delas é o que Brenner chama de "ofensiva patronal" (Employer's Offensive) cujo objetivo era recuperar as taxas de lucro dos Trinta Anos Gloriosos. O neoliberalismo aparece como tentativa de responder ao baixo crescimento dos últimos anos da Era de Ouro do capitalismo. A pressão exercida sobre os trabalhadores no sentido da retirada de direitos e diminuição salarial tinha foi busca de superação das baixas taxas de lucro, cada vez mais decrescentes. É importante notar que, embora levada cabo por governos como os de Reagan e Thatcher, sua raiz reside numa crise de valorização mais profunda, não sendo redutível à dimensão política. $\mathrm{O}$ fundamento histórico do longo declínio é a incapacidade de contornar o excesso de produção na indústria, o que poderíamos chamar de crise de superprodução:

\footnotetext{
${ }^{8}$ No original: "I attempt to demonstrate that the way in which this pattern of uneven development worked itself out supports my more general interpretation of the long downturn in terms of intensified competition leading to over-capacity and over-production and a secular fall in profitability, especially in manufacturing" (BRENNER, 2006, p. 9).
} 


\section{Revista \\ Debates Insubmissos}

(...) a ascensão do capital financeiro e do neoliberalismo deve ser vista muito mais como consequência do que como causa da crise internacional - mesmo que eles a tenham exacerbado significativamente. A crise, por sua vez, tem suas raízes profundas numa crise secular da lucratividade que resultou do excesso constante de capacidade e de produção no setor manufatureiro internacional. (BRENNER, 1999, p. 12)

Robert Brenner rompe com a leitura politicista segundo a qual o neoliberalismo é uma estratégia de uma classe globalmente organizada orientada para a destruição dos ganhos democráticos que teriam feito frente à irracionalidade do capitalismo. Em seu lugar, entende o neoliberalismo como sintoma de uma crise sistêmica mais profunda, sendo não o contrário do Estado de Bem-Estar Social mas o seu herdeiro legítimo, na medida em que se propõe a continuar a tarefa que aquele já não mais conseguia realizar, a saber, a de manter taxas altas de crescimento econômico. O Estado de Bem-Estar Social ruiu a partir de dentro, devido à dinâmica da concorrência global, de tal forma que aquele suposto crescimento expansivo e estável era, em verdade, a preparação do caminho para as crises cada vez mais constantes. A "Era de Ouro" do capitalismo não foi o modelo de funcionamento desejável do capitalismo ou o ideal do passado que deveríamos lutar para voltar, mas a exceção momentânea e sem retorno de uma dinâmica capitalista cujo ponto de chegada é a crise em que estamos. As teses de Brenner permitem sustentar que as dinâmicas do capitalismo do Welfare State são as subjacentes ao capitalismo neoliberal.

É importante sublinhar que, apesar da boa análise de Brenner, é sintomático como ele não se debruça devidamente acerca de como o Estado de Bem-Estar Social se tornou possível e obteve estabilidade a partir da dominação dos países centrais em relação à periferia do capitalismo, entendendo por periferia aqui países mais além de Alemanha e Japão. Por exemplo, a manutenção da colonização da África era o outro lado da moeda necessário ao desenvolvimento desigual e combinado da chamada Era de Ouro do capitalismo. Intelectuais como Franz Fanon (2005) e Achille Mbembe (2014) são bastantes precisos nesse ponto de compreender o capitalismo como um sistema mundial numa chave de desenvolvimento desigual e combinado mais ampla.

Quais os efeitos psíquicos dessa passagem histórica do Estado de Bem-Estar Social ao neoliberalismo dinamizada pela crise do capitalismo? Essa questão mobiliza as obras $O$ 
mínimo eu: estratégias de sobrevivência psíquica em tempos de crise, de Christopher Lasch (1986), e A corrosão do caráter: consequências pessoais do trabalho no novo capitalismo, de Richard Sennett (2014) ${ }^{9}$. Ambos estão preocupados com a maneira pela qual os indivíduos suportam tais mudanças que lhes aparecem como objetivas, externas e das quais eles não possuem controle algum e nada podem fazer, exceto grandes esforços psíquicos de adaptação. O pressuposto básico é o de que o mercado se transforma numa norma de vida interior que deve regular a conduta e o pensamento dos indivíduos, para além de uma dinâmica objetiva de troca de mercadorias.

O que significa sobreviver psiquicamente num contexto destrutivo marcado pelo longo declínio? De que modo o psiquismo mantém sua estabilidade num quadro como esse? Como sobrevivemos num mundo em que o futuro já não é mais o lugar das realizações das promessas do presente, mas sim a vinda de desastres que todos nós aguardamos? Segundo Lasch (1986, p. 9), o equilíbrio emocional nesses tempos de crise neoliberal é um "eu mínimo, não o eu soberano do passado".

Em sua obra mais conhecida, é comum prestar mais atenção no título A Cultura do Narcisismo (LASCH, 1983), do que no subtítulo Vida americana numa Era de Esperanças em Declínio. No entanto, talvez seja a perda do horizonte positivo do futuro que constitua o ponto mais importante de seu argumento, na medida em que o narcisismo não aparece como o engrandecimento do indivíduo particular, mas sim, ao contrário, como uma preocupação com a sobrevivência psíquica na manutenção de um eu cada vez mais diminuto:

A expectativa de que a ação política pudesse humanizar gradualmente a sociedade industrial deu lugar a uma determinação de sobreviver em meio ao naufrágio geral, ou, mais modestamente, de manter intacta a própria vida, face às crescentes pressões. O risco de desintegração individual estimula um sentido de individualidade que não é "soberano" ou "narcisista", mas simplesmente sitiado (LASCH, 1986, p. 10).

\footnotetext{
${ }^{9}$ A edição francesa (da editora Flammarion) do livro de C. Lasch torna ainda mais explícita essa possibilidade de diálogo, porque põe "Le moi assiégé: essai sur l'érosion de la personnalité", algo como "O eu sitiado: ensaio sobre a erosão da personalidade". A erosão designa o processo que desde fora danifica ou desgasta algo. Ela se aproxima bastante do processo de corrosão que será tomado por Sennett, porque ambos os processos se referem à deterioração de um material por ação externa constante.
} 


\section{Revista \\ Debates Insubmissos}

É, desse modo, um “eu mínimo” que deve restar nos processos de socialização numa sociedade em declínio e em crise. Na erosão da esfera pública que garantia estabilidade, resta ao indivíduo voltar-se a si mesmo. Em uma das frentes, voltar-se a si mesmo como empreendedor de si mesmo, como aquele que, isolado e jogado num mundo hostil, sem nenhuma garantia do êxito de suas ações, tem que ganhar a vida por si mesmo. Portanto, quando não se pode mudar o mundo, o que resta é reinventar a si mesmo. A "cultura do narcisismo", ao contrário do que parece, é um tipo de cultura de sobrevivencialismo em tempos de crise, um programa de "mentalidade sitiada". Não é uma cultura em que há muito eu, mas, pelo contrário, uma cultura na qual o eu é constantemente reduzido a funções sociais de maneira precária:

O narcisismo significa uma perda da individualidade e não a auto-afirmação; referese a um eu ameaçado com a desintegração e por um sentido de vazio interior. Para evitar confusão, o que eu denominei a cultura do narcisismo seria melhor caracterizado, ao menos para o momento, como a cultura do sobrevivencialismo. A vida cotidiana passou a pautar-se pelas estratégias de sobrevivência impostas aos que estão expostos à extrema adversidade (LASCH, 1986, p. 47).

A afirmação existencial da individualidade atomizada passa a ser a única resposta adequada às situações extremas provocadas pela crise estrutural do capitalismo. A lição de Lasch é a de que a crise não denota somente um funcionamento social amplo específico do modo de produção de mercadorias, nem somente um colapso das instituições sociais, mas principalmente um conjunto de transformações psíquicas nos indivíduos que acompanha a crise estrutural.

Em Richard Sennett, em paralelo ao desfazimento do Estado de Bem-Estar Social se dá a corrosão do caráter, ou seja, a destruição lenta das formas de subjetividades produzidas naquele arranjo social. O título do primeiro capítulo de seu livro é cristalino: como o novo capitalismo ataca o caráter pessoal. Sennett (2014, p. 10) argumenta que o novo capitalismo flexível modifica substancialmente o caráter, o qual ele define como "traços pessoais a que damos valor em nós mesmos, e pelos quais buscamos que os outros nos valorizem". 


\section{Revista
Debates Insubmissos}

A geração que veio após a Segunda Guerra Mundial tinha o mundo sob controle por conta das garantias do Estado e das empresas que produziam relativa estabilidade econômica e também a sustentação firme dos direitos individuais, sociais e políticos. No entanto, como Sennett (2014, p. 23) sublinha, esse período dos Trinta Anos Gloriosos é contestado pelo trabalho temporário, flexível. Ainda que não fosse o melhor dos cenários, "o tempo rotinizado se tornara uma arena onde os trabalhadores podiam afirmar suas próprias exigências, uma arena que dava poder", diz Sennett (2014, p. 48), sobre o solo das lutas sociais e de formação de caráter da era de ouro do capitalismo. Porque "se por um lado é uma prisão, a jaula de ferro também pode, assim, tornar-se um lar psicológico" (SENNETT, 2019, p. 14).

A flexibilidade se opõe à rotina. $\mathrm{O}$ trabalhador flexível é aquele que pode ser adaptado a circunstâncias variáveis, mas não quebrado por elas. Essa resiliência, para usar um vocábulo da ordem do dia, é a matéria-prima dessa subjetividade necessária ao capitalismo neoliberal. O trabalhador da era de ouro tinha seus valores sólidos, nos quais ele ancorava seu caráter. Já o trabalhador flexível precisa constantemente ceder em seus pontos de vista, caso contrário será enviado para o exército industrial de reserva como mais um desempregado. A flexibilidade não é somente um dado do trabalho como prática produtiva, mas também como esfera de produção de subjetividade. Ela sinaliza a corrosão do caráter, a destruição lenta dos valores morais que regiam o mundo do trabalho na perspectiva da classe operária.

Tais mudanças não libertaram as pessoas, como prometido. A ideia de "deriva" é usada por Sennett para descrever a sensação subjetiva de experimentar tais mudanças psíquicas relacionadas ao mundo do trabalho em tempos neoliberais. Ele analisa o fosso que separa as gerações de Enrico e Rico - pai e filho cujas vidas expressam a diferença entre gerações no "novo capitalismo" - como dois modos de vida distintos: uma que se tece no tempo linear e previsível, por um lado, e uma submetida ao imperativo "não há longo prazo", por outro. A respeito de Rico, diz Sennett (2014, p. 19): "Ele temia que que as medidas que precisava tomar e a maneira como tinha de viver para sobreviver na economia moderna houvessem posto sua vida emocional, interior, à deriva”. A convergência da analogia da 


\section{Debates Insubmissos}

Revista

marítima (naufrágio e deriva) usada por Lasch e Sennett expressam bem os modos de subjetivação em tempos de razão instrumental neoliberal.

Para ambos, o processo de desregulamentação da economia trouxe consigo a desregulamentação do psiquismo, isto é, as bases sólidas e duradouras que regiam o psiquismo passam a ser flexibilizadas e desmontadas. De maneira análoga às análises de Brenner, o eu mínimo decorre lógica e historicamente do eu soberano, na medida em que se perderam as condições objetivas de um e somente resta a possibilidade do outro. Ou seja, ambos permitem problematizar a transformação da ordem subjetiva que se dá num quadro social regressivo marcado pelas turbulências da crise.

\section{O MAL-ESTAR DO PÓS-NEOLIBERALISMO}

As dinâmicas sociais e psíquicas talvez tenham ido mais além do que tematizaram Robert Brenner, Christopher Lasch e Richard Sennett. A derrocada do Estado de Bem-Estar Social pelo neoliberalismo como estratégia de contenção da crise do ponto de vista da objetividade histórica e a mudança da norma subjetiva da estabilidade para a flexibilidade do ponto de vista subjetivo compuseram a vitalidade da razão instrumental neoliberal a partir da década de 1970. Esses três intelectuais, cada um em seu nível de análise, pressupõem certa estabilidade no declínio, como se a conjuntura histórico-política e subjetiva conseguisse se arranjar de maneira frágil, porém duradoura.

Modificando seu dinamismo burocrático e estático, a razão instrumental assumiu o avatar neoliberal pelos mecanismos de desregulação tanto econômica quanto psíquica como uma nova forma histórica de sujeição. O horizonte da razão instrumental neoliberal ainda era produtivo, pois se tratava de adequar o psiquismo dos sujeitos à esfera econômica em mutação, o que significou, como analisado por Sennett e Lasch, a corrosão do caráter e o mínimo eu como estratégias de sobrevivência.

O arranjo neoliberal, marcado pela informalidade e flexibilidade, teve como função histórico-objetiva retardar e conter os efeitos da crise do capital deflagrada na década de 1970, 


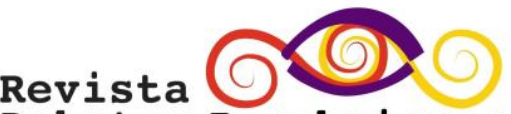 \\ Debates Insubmissos}

como Brenner demonstrou. Embora tenha obtido relativo êxito do ponto de vista das exigências de valorização do capital, ao menos no centro pois na periferia (como na África e na América Latina) a barbárie continuou sendo a tônica ${ }^{10}$, hoje se encontra em processo de esgotamento. Estamos no fim do neoliberalismo e isso não é exatamente um dado positivo ou promissor, como se aquilo que se avizinhasse fosse melhor do que o estado atual de coisas.

A dinâmica de um eu "ameaçado com a desintegração e por um sentido de vazio interior" que pode encontrar saída numa cultura do sobrevivencialismo se radicalizou. Pois a própria manutenção de uma esfera como o eu, entendida como instância envolvida no embate entre pulsões agressivas e normas sociais, parece abrir espaço a outros modos de subjetivação. Ocorre hoje uma adesão quase total do eu aos mecanismos do mercado. Aquele diagnóstico de Adorno e Horkheimer nos anos 1940 permanece atual, ou seja, há uma tendência à integração total no interior do mundo administrado no qual o indivíduo habita.

Marildo Menegat (2012) utiliza a imagem da ruína para descrever o presente histórico. A ruína, para ele, denota um mundo que desmorona mas se mantém ao mesmo tempo. Essa imagem demarca também a dissolução passiva do capitalismo, ou seja, na ausência do sujeito coletivo capaz de negar a sociedade existente, essa própria sociedade procura se manter brutalmente apesar do colapso de sua forma estruturante básica, a mercadoria. Nesse quadro, a decomposição se impõe sobre as formas de sociabilidade (expressa na militarização das favelas e no crescimento do sistema punitivo, p. ex.) bem como sobre as formas de subjetividade, como comprovam a assunção, por parte dos sujeitos, de formas regressivas de contenção da crise estrutural ou mesmo o funcionamento da ideologia que passou a ser o de digerir a crise por meio da personificação dos efeitos de barbárie que ela gera, como se, para dar um exemplo, a crise fosse resultado da ação de grupos como a população LGBTQI+, negros, mulheres, índios, dentre outros, e não o resultado lógico do atual estágio do capitalismo. Em termos da razão instrumental neoliberal, "estamos, ao que tudo indica,

\footnotetext{
${ }^{10}$ Talvez Herbert Marcuse (2015) tenha sido, dentre os frankfurtianos, o que mais percebeu essa dinâmica mais global do capitalismo ao propor que se deve entender o Estado de Bem-Estar Social (Welfare State) como sendo complementado pelo Estado de Guerra (Warfare State).
} 
cavalgando mais um círculo ampliado da dialética do Iluminismo" (MENEGAT, 2006, p. 88). O neoliberalismo foi a tentativa de gerir a barbárie, ou seja, de conter a crise do capitalismo por meio da regressão social (pauperização, desemprego estrutural, retirada de direitos etc.). Essa "gestão da barbárie" funcionou a nível mundial, bem como a nível nacional, sobretudo entre 2008-2013. Estamos, agora, no "fim da gestão da barbárie", no interior da qual se trata de "livrar-se fisicamente dos perdedores da competição global” (MENEGAT, 2019a, p. 99).

Esse momento histórico de colapso da racionalidade instrumental neoliberal é marcado pela "dessocialização catastrófica" (KURZ, 2014), ou seja, um deslocamento do processo outrora intencionalmente orgânico das formações sociais modernas, que produziam sua unidade em torno da dinâmica imanente da identidade das "máscaras de caráter" constitutivas dessa forma social: "como essa unidade foi implodida pela crise, seu lugar vai sendo ocupado por relações sociais sustentadas no uso direto da violência, que procura manter conectado o que ainda funciona da reprodução social da velha ordem agônica" (MENEGAT, 2019a, p. 128). Essa relação entre colapso da racionalidade instrumental neoliberal e dessocialização catastrófica pode ser lida na chave de que uma das características do capitalismo é "reduzir em grande medida a forma da existência dos indivíduos às necessidades da economia" (MENEGAT, 2019a, p. 120). Com a agudização da crise estrutural do capitalismo, essa redução ao econômico da existência gira em falso, pois não se consegue mais promover integração social, tornando supérfluas grandes massas humanas, desnecessárias ao modo de produção capitalista.

Mas, o que ocorre com os sujeitos numa quadra histórica em que o sucesso não está mais no campo de possibilidades de ser? Qual o impacto do colapso da razão instrumental neoliberal no campo do psiquismo? O que ocorre depois de o mercado se tornar a norma da vida psíquica? Em outras palavras, quando o mercado se encontra também em processo de crise e regressão, quais são os efeitos psíquicos que isso gera? A crise da razão instrumental neoliberal intensifica os processos de regressão não apenas, por exemplo, no campo dos direitos adquiridos, produzindo desemprego estrutural e miséria disseminada, mas também no campo do psiquismo, radicalizando aqueles efeitos analisados por Lasch e Sennett. 
A partir deles é possível tematizar como as mudanças neoliberais também fizeram com que se alterassem os modos de sofrimento psíquico. Porque, como diz Jorge Coelho Soares (2000, p. 221), “formas específicas de sofrimento psíquico podem ser derivadas e diretamente associadas à dinâmica de um dado projeto econômico-político”, a tarefa atual da crítica é pensar quais modos de sofrimento se apresentam nesse contexto de ruína. De um lado estão a mercadoria e o capital como bases da sociabilidade capitalista ancorada no trabalho. Contudo, em tempos de desemprego estrutural, esse dinamismo gira em falso. Num nível mais fenomênico, ocorre a gestão das populações supérfluas, por meio da marcha fúnebre da necropolítica que atua na realização do apartheid e da matança de corpos periféricos das grandes metrópoles (MBEMBE, 2003). Essas populações geridas necropoliticamente já estão fora do circuito do sucesso neoliberal (que significa ter dinheiro suficiente disponível), são corpos entendidos como aquém do empreendedorismo de si mesmo. Corpos sem valor. Sujeitos monetários sem dinheiro. Vivemos tempos nos quais "a humanidade não cabe mais nos cálculos da economia" (MENEGAT, 2019a, p. 196). O problema da atualidade é o da falência dessas estratégias psíquicas de adesão ao mundo do trabalho. Nesse sentido:

Já não há trabalhadores propriamente ditos. Já só existem nômadas do trabalho. Se, ontem, o drama do sujeito era ser explorado pelo capital, hoje a tragédia da multidão é não poder já ser explorada de todo, é ser objeto de humilhação numa humanidade supérflua, entregue ao abandono, que já nem é útil ao funcionamento do capital (MBEMBE, 2014, p. 14).

Mbembe chama esse caráter descartável e solúvel generalizado ao mundo inteiro como “devir-negro do mundo" (MBEMBE, 2014, p. 18). No que interessa aqui, tornar-se supérfluo ao mundo do trabalho inserido numa sociedade que impõe a sujeição ao trabalho como momento necessário de socialização é a condição inédita da atualidade.

Tomo como exemplo o campo da educação para analisar o estado atual de coisas: a educação anterior visava substituir o princípio de prazer pelo princípio de realidade, sem aniquilá-lo totalmente, gerando sujeitos neuróticos como horizonte viável para o estabelecimento de laços sociais e funcionamento social. Na era de ouro do capitalismo, a escola foi uma instituição que participava do projeto da modernidade no sentido de produzir uma padronização de corpos dóceis politicamente e úteis produtivamente na direção de uma 


\section{Revista (O) \\ Debates Insubmissos}

“subjetivação capitalista”, isto é, realizar a inserção de cada um dos indivíduos no universo da produção de mercadorias por meio do emprego (FOUCAULT, 1987). Portanto, a escola era portadora da promessa integradora da educação (GENTILI, 2012).

A educação do neoliberalismo modificou essa conjuntura através da adoção do modelo do sujeito empresarial como matriz de produção de subjetividade. No contexto inicial da razão instrumental neoliberal, ainda não estavam claros os impactos do desemprego estrutural sobre a educação. Por conta do desemprego estrutural e crônico, a educação não é mais capaz de garantir, para um conjunto amplo de pessoas, o trabalho como emprego fixo, isso significa uma aniquilação da educação um nome da empregabilidade. Ou seja, a escola já não tem mais como objetivo a formação de um contingente de trabalhadores técnicos e capazes de produção de riqueza, mas sim de contribuir para o fortalecimento da "empregabilidade individual".

A possibilidade de um horizonte coletivo seguro se quebrou - a garantia de um emprego depois da formação escolar - e, em seu lugar, foi colocada uma saída hiperindividualista. A educação passou a ser um bem econômico pertencente aos indivíduos. Ela possibilita aos alunos (encarados como empreendedores de si) capitalizarem seus recursos privados na direção de rendimentos futuros. A educação é, então, vista como um investimento individual e não mais como parte integrante do projeto democrático. Nesse contexto, a educação enquanto projeto de formação de indivíduos adotou sem restrições o modelo da empresa como norma de produção de subjetividade.

O grande problema dessa saída hiperindividualista é que a educação acaba colocando no colo do indivíduo-aluno a resolução de um problema objetivo, histórico e amplo. $\mathrm{O}$ emprego nunca foi um problema individual, mas sempre um problema de planejamento econômico ampliado. No entanto, hoje o emprego é posto como questão de empregabilidade e, assim, de esforço individual. No segundo tempo da razão instrumental neoliberal, ocorre a desintegração da promessa integradora da educação (GENTILI, 2012). A resolução do emprego em termos individuais de empregabilidade, no primeiro tempo da razão instrumental neoliberal, apresentava o lado positivo do empreendedorismo, isto é, da criatividade, inventividade, autonomia etc. 


\section{Revista \\ Debates Insubmissos}

No entanto, essa psicologização do sucesso e da conquista do emprego desde o início se apresentou também de maneira negativa por meio de novas psicopatologias como a síndrome de Burnout (HAN, 2015) e a depressão (EHRENBERG, 1998). No segundo tempo da razão instrumental neoliberal, o do seu colapso, a face bárbara dessa saída hiperindividualista se torna a tendência da relação do sujeito com a sociedade capitalista. Zygmunt Bauman é preciso em sua "análise de disjuntura"11:

Os jovens da geração que agora está entrando ou se preparando para entrar no chamado "mercado de trabalho" foram preparados e adestrados para acreditar que sua tarefa na vida é ultrapassar e deixar para trás as histórias de sucesso de seus pais; e que essa está totalmente dentro de suas possibilidades. Não importa aonde os pais conseguiram chegar, eles chegarão mais longe. Pelo menos é assim que foram ensinados e doutrinados. Nada os preparou para a chegada do novo mundo inflexível, inóspito e pouco atraente, o mundo da degradação dos valores, da desvalorização dos méritos obtidos, das portas fechadas, da volatilidade dos empregos e da obstinação do desemprego; da transitoriedade das expectativas e da durabilidade das derrotas; um novo mundo de projetos natimortos e esperanças frustradas, e de oportunidades mais notáveis por sua ausência. (BAUMAN, 2013, p. 45).

Se a sobrevivência psíquica já era frágil nos tempos em que a razão instrumental neoliberal funcionava a plenos pulmões, agora que ela dá sinais de esgotamento, torna-se ainda mais difícil para os sujeitos se estabilizarem psiquicamente. Os próprios sujeitos introjetam essa destrutividade oriunda do desfazimento da razão instrumental neoliberal. A concorrência é assimilada no espaço educacional como uma guerra perpétua na qual cada um, para sobreviver, deve se isolar com fria indiferença e também tratar com agressividade selvagem tudo o que for obstáculo - inclusive dentro de si mesmo - ao êxito no mercado:

Esta educação prepara simplesmente as crianças para viverem no "novo espírito" do capitalismo, cujos valores proclamados, como dissemos, se opõem amiúde aos antigos sem que por isso os indivíduos sejam mais livres ou se sintam mais realizados. Nas duas formas de educação, as pessoas conservam, muitas vezes

\footnotetext{
${ }^{11}$ Uso aqui livremente essa expressão que é de autoria de Frédéric Vandenberghe. Ele a utilizou na ementa de uma disciplina que ele ministrou no segundo semestre de 2019 no Instituto de Filosofia e Ciências Sociais da Universidade Federal do Rio de Janeiro (IFCS-UFRJ) chamada "Ontologia do presente: neoliberalismo, antropoceno, populismo" e me parece sinalizar uma análise de um momento histórico que se apresenta na forma da decomposição. Conjuntura alude à combinação de acontecimentos num dado momento, enquanto disjuntura passa a ideia de que esse momento é aquele no qual os elementos não se combinam mas sim se desagregam. Nesse caso específico, ocorre a desagregação da educação, do mercado e da democracia.
} 


\section{nevistet \\ Debates Insubmissos}

durante toda a vida, uma recordação submersa dos traumas infantis, que podem reactivar-se e desembocar num acto violento ou suicida e, nos casos mais extremos, numa matança de massas. (JAPPE, 2019, p. 279).

O sujeito que está no horizonte da norma neoliberal adotada pela sociedade atual, e consequentemente também pela escola, é o "flexível", o qual, do ponto de vista do psiquismo, é também aquele que se desfaz de todas as inibições sociais para se tornar capaz de tudo. Isso levou intelectuais como DOUGLAS KELLNER (2008), ROBERT KURZ (2002) e ANSELM JAPPE (2019) a analisar a ligação entre o amoque $^{12}$ e o capitalismo. O colapso da racionalidade instrumental neoliberal se dá pela penetração da abstração real da mercadoria nas mais profundas dimensões psíquicas, transformando cada sujeito numa paisagem gelada de sentimentos e processos psíquicos congelados, frios.

A democracia da economia de mercado chora lágrimas de crocodilo pelas suas crianças perdidas em massacres. Crianças as quais ela submete constantemente por meio de uma educação cujo horizonte é se tornar um exímio concorrente egocêntrico, disciplinado e adoecido. Na derrota dessa travessia ao sucesso, o ódio emerge como certeza do sujeito em relação à sua nulidade e superfluidade. O colapso da racionalidade instrumental neoliberal produz assassinos amoque e suicidas como sujeitos da crise (KURZ, 2002). Trata-se da junção paradoxal da produção destrutiva de subjetividade capitalista com o desfazimento da substância do capital.

A necropolítica se impõe e se torna a tendência em crescimento desse mundo em colapso. Ela pode ser definida como a "destruição material dos corpos e populações humanos julgados como descartáveis e supérfluos” (MBEMBE, 2012, p. 135). Portanto, a necropolítica é a gestão dos sobrantes, dessas massas que são o produto das práticas neoliberais, o exército permanente de reserva do desemprego estrutural. Ela também pode ser definida como modo

\footnotetext{
${ }^{12}$ Amok/amoque, termo oriundo do português "amouco" em voga no século XVI, que significa "cheio de fúria, tomado de furor homicida, votado à morte, desesperadamente obcecado, desvairado". É um fenômeno específico dos povos da Malásia, Laos, Filipinas, Porto Rico, dentre outros, e se refere, em sua origem, aos guerreiros cuja luta não conhecia precaução nem cautela e muitas vezes se assemelhava a suicídios coletivos, podendo ser lido também como uma "possessão homicida" (SOFSKY, 2004), tendo assim origem no termo malaio meng-âmok, que significa "atacar e matar com ira cega". Chegou a ser considerado no DSM-IV no item Fuga Dissociativa, 300.13. No DSM-V, essa leitura parece ter sido retirada. Essa síndrome foi descrita psicopatologicamente pela primeira vez em 1972 pelo psiquiatra estadunidense Joseph Westermeyer (1985).
} 
de regulação psíquica em tempos de declínio, fazendo emergir e se ampliar a figura do sujeito supérfluo, l'homme jetable (OGILVIE, 2012), cuja existência objetiva está fora do circuito social e a regulação psíquica está abalada, pois na medida em que o sujeito se vê devorado pelo receio de que seu psiquismo se dissolva inteiramente, resta apenas a agressão (seja dirigida para si mesmo por meio da depressão, p. ex., ou para os outros por meio da aniquilação) como maneira desesperada de conservar a integridade de seu eu nulo.

Jappe (2018, p. 283) compreende que a eliminação do trabalho liberta também energias destrutivas, as quais anteriormente estavam ligadas ao trabalho e passam agora a vaguear livremente no espaço social, de maneira muito diferente, por exemplo, daquela analisada por Norbert Elias (1993, p. 201) na passagem do controle social ao autocontrole, baseado num superego que controla, transforma ou suprime as emoções em conformidade com a estrutura social: "A agência controladora que se forma como parte da estrutura da personalidade do indivíduo corresponde à agência controladora que se forma na sociedade em geral". O controle da violência do cotidiano aparece em Elias como evidência histórica da tendência do processo civilizador, no entanto, os processos de descivilização ou as pressões descivilizadoras caminham como sua sombra, de modo que a questão é saber "quais são as forças que levam a melhor, a curto e a longo prazo: as centrífugas ou as centrípetas" (MENNELL, 2001, p. 163). A tendência da atualidade parece agir no sentido da dissolução, como se o presente fosse marcado por um "corte qualitativo deste exercício cotidiano das pressões descivilizadoras" (MENEGAT, 2019b, p. 8).

Isso pode ser denominado - com inspiração livre na noção de "identificação com o existente" (ADORNO, 1995, p. 43) - como adesão psíquica à barbárie, isto é, quando os próprios indivíduos subjetivam/corporificam esse modo de ser em colapso, assumem para suas próprias existências as normas sociais em frangalhos do capitalismo. Subjetivam tanto no sentido de se sujeitarem à razão econômica em ruínas como única forma de existir nesse mundo, quanto no sentido de internalizarem os mecanismos da concorrência, tornando-a forte do ponto de vista da norma que regula o psiquismo, no momento em que mais ela se enfraquece como horizonte de possibilidades para grandes massas humanas, pois já não 
promove nenhum tipo de inserção social. Os atos de destrutividade são a realização do "homem flexível" exigido pela economia, essa figura subjetiva que deve se desfazer de todas as inibições para se tornar capaz de qualquer tarefa que o mundo lhe exigir de maneira direta e sem qualquer justificação discursiva que oriente suas práticas.

Como bem analisou Adorno (2020) em 1967, as ideologias e os modos de inscrição individual na sociedade capitalista assumem uma forma demoníaca, verdadeiramente destrutiva, quando os sujeitos se veem submetidos a contextos objetivos em relação aos quais são impotentes. Na conjuntura atual, sujeitos se sentem, além de impotentes, também supérfluos. A consequência disso é a emergência do amoque depois do empreendedor de si mesmo do primeiro tempo da razão instrumental neoliberal, como novo sujeito da política, um necroativista que não almeja nada mais que não seja a destruição de tudo e de todos, a exemplo das carreatas da morte e nos atos no Brasil em tempos de pandemia. Ele já não é mais exatamente o explorado, que força o explorador a reconhecê-lo, porque dele também depende e que possui um projeto civilizatório menos destrutivo. A crise das formas de socialização do capitalismo produz um número cada vez maior de seres humanos não rentáveis e supérfluos, o que produz raiva e ódio nesses “detritos humanos” (JAPPE, 2019, p. 292), gerando ações de barbárie e de aniquilamento, muito distante do horizonte perdido da luta de classes, cujo horizonte era a solidarização dos laços sociais.

\section{REFERÊNCIAS}

ADORNO, T. A dialética negativa. Rio de Janeiro: Jorge Zahar, 2009.

ADORNO, T. Aspectos do novo radicalismo de direita. Lisboa: Edições 70, 2020.

ADORNO, T. O ensaio como forma. In Notas de Literatura I. São Paulo: Ed. 34, 2003.

ADORNO, T. O que significa elaborar o passado? In Educação e emancipação. São Paulo: Paz e Terra, 1995.

ADORNO, T. Três estudos sobre Hegel. Rio de Janeiro: Editora UNESP, 2013.

ADORNO, T; HORKHEIMER, M. A dialética do Esclarecimento: Fragmentos filosóficos. Rio de Janeiro: Jorge Zahar: 1985. 
BAUMAN, Z. Sobre educação e juventude. Rio de Janeiro: Jorge Zahar, 2013.

BRENNER, R. A economia da turbulência global. Praga: Revista de Estudos Marxistas, São Paulo, n. 7, 1999.

BRENNER, R. O boom e a bolha. Rio de Janeiro: Record, 2002.

BRENNER, R. Economics Of Global Turbulence: The Advanced Capitalist Economies from Long Boom to Long Downturn, 1945-2005. New York: Verso, 2006.

DUMÉNIL, G.; LÉVY, D. A crise do neoliberalismo. São Paulo: Boitempo, 2014.

EHRENBERG, A. La fatigue d'être soi. Dépression et société. Paris: Éditions Odile Jacob, 1998.

ELIAS, N. O processo civilizador. Volume 2: Formação do Estado e Civilização. Rio de Janeiro: Jorge Zahar, 1993.

FANON, F. Os Condenados da Terra. Juiz de Fora: Ed. UFJF, 2005.

FORTIER, F.; LAVALLÉ, L.-F. Robert Brenner. In MARTINEAU, J. Marxisme anglosaxon: figures contemporaines. Québec : Lux Éditeur, 2013.

FOUCAULT, M. Vigiar e punir: o nascimento das prisões. Petrópolis: Vozes, 1987.

FREYENHAGEN, F. O que é teoria crítica ortodoxa? Dissonância: Revista de Teoria Crítica, v. 3, 15 nov. 2018.

GANDLER, S. Fragmentos de Frankfurt: ensayos sobre la teoría crítica. México: Siglo XXI Editores, 2009.

GEISELBERGER, H. (org.). A Grande Regressão: um debate internacional sobre os novos populismos - e como enfrentá-los. São Paulo: Estação Liberdade, 2019.

GENTILI, P. Educar para o desemprego: a desintegração da promessa integradora. In FRIGOTTO, G. (org.). Educação e crise do trabalho. Petrópolis: Ed. Vozes, 2012.

HAN, B.-C. A sociedade do cansaço. Petrópolis: Vozes, 2015.

HORKHEIMER, M. A presente situação da filosofia social. In Praga: Estudos Marxistas, 7, 1999, pp. 121-132.

HORKHEIMER, M. Eclipse da razão. São Paulo: Centauro, 2002.

JAPPE, A. A sociedade autofágica: capitalismo, desmesura e autodestruição. Lisboa: Antígona, 2019.

JAY, M. A imaginação dialética: História da Escola de Frankfurt e do Instituto de Pesquisas Sociais, 1923-1950. Rio de Janeiro: Contraponto, 2008.

KELLNER, D. Guys and Guns Amok. New York: Routledge, 2008.

KURZ, R. A crise do valor de troca. Rio de Janeiro: Consequência, 2018a. 
KURZ, R. A honra perdida do trabalho. Lisboa: Antígona, 2018b.

KURZ, R. A pulsão de morte da concorrência: assassinos amoque e suicidas como sujeitos da crise. Jornal Folha de São Paulo, ano 82, nº 15.357, 26 mai. 2002.

KURZ, R. Dinheiro sem valor - linhas gerais para uma transformação da crítica da economia política. Lisboa: Antígona, 2014.

KURZ, R. O colapso da modernização: da derrocada do socialismo de caserna à crise da economia mundial. Rio de Janeiro: Paz e Terra, 1993.

LASCH, C. A cultura do narcisismo: a vida americana numa Era de Esperanças em Declínio. Rio de Janeiro: Imago, 1983.

LASCH, C. O mínimo eu: sobrevivência psíquica em tempos difíceis. São Paulo: Brasiliense, 1986.

MARCUSE, H. O homem unidimensional. São Paulo: EDIPRO, 2015.

MARTINEAU, J. Marxisme anglo-saxon: figures contemporaines. Québec : Lux Éditeur, 2013.

MBEMBE, A. Crítica da Razão Negra. Lisboa: Antígona, 2014.

MBEMBE, A. Necropolitics. Public Culture, v. 15, p. 11-40, 2003.

MBEMBE, A. Necropolítica, una revisión crítica, in Helena Chávez Mac Gregor (Coord.),

Estética y violencia: Necropolítica, militarización y vidas lloradas, UNAM-MUAC, México, 2012.

MENEGAT, M. A crítica do capitalismo em tempos de catástrofe. Rio de Janeiro: Consequência, 2019a.

MENEGAT, M. Estudos sobre Ruínas. Rio de Janeiro: Revan, 2012.

MENEGAT, M. Depois do fim do mundo: a crise da modernidade e a barbárie. Rio de Janeiro: Relume Dumará, 2003.

MENEGAT, M. O olho da barbárie. São Paulo: Expressão Popular, 2006.

MENEGAT, M. Violência e Barbárie: um pequeno estudo sobre as origens remotas do bolsonarismo. In Argum., Vitória, v. 11, n. 2, p. 7-16 maio/ago. 2019b.

MENNELL, S. O reverso da medalha: os processos de descivilização. In: GARRIGOU, A.; LACROIX, B. Norbert Elias: a política e a história. São Paulo: Perspectiva, 2001.

NATCHWEY, O. Desvivilização - Sobre tendências regressivas nas sociedades ocidentais. GEISELBERGER, H. (org.). A Grande Regressão: um debate internacional sobre os novos populismos - e como enfrentá-los. São Paulo: Estação Liberdade, 2019.

OGILVIE, B. L'Homme Jetable. Essai sur l'exterminisme et la violence extrême. Paris : Editions Amsterdam, 2012. 
PECK, J.; THEODORE, N.; BRENNER, N. Mal-estar no pós-neoliberalismo. Novos estud. - CEBRAP, São Paulo, n. 92, p. 59-78, Mar. 2012.

POLLOCK, F. State Capitalism: Its Possibilities and Limitations. In ARATO, A.; GEBHARDT, E. The Essential Frankfurt School Reader. New York: Continuum, 1990.

SENNETT, R. A cultura do novo capitalismo. Rio de Janeiro: Record, 2019.

SENNETT, R. A corrosão do caráter: consequências pessoais do trabalho no novo capitalismo. Rio de Janeiro: Ed. Record, 2014.

SOARES, J. C. A crise da sociedade contemporânea e o sofrimento psíquico. In Revista Ciências Humanas, Rio de Janeiro, v. 23, n. 1-2, pp. 220-231, jun.-dez. 2000.

SOFSKY, W. Tiempos de horror: Amok, violencia, guerra. Madrid: Siglo XXI, 2004.

STREECK, W. Tempo Comprado: a crise adiada do capitalismo democrático. Lisboa: Editora Actual, 2013.

WESTERMEYER, . Sudden Mass Assault with Grenade: An Epidemic Amok Form from Laos. In SIMONS, R. (ed.). The Culture-Bound Syndromes: Folk Illnesses of Psychiatric and Antropological Interest. Boston: D. Reidel Publishing Company, 1985.

Submetido em: 25/09/2019

Aprovado em: 19/05/2020 